\title{
Mastering the art of conversation in pediatrics - the key in preventing diagnostic errors
}

\author{
Stefana Cristina Alexoaie ${ }^{1,2}$, Diana Veronica Turcul ${ }^{1,3}$, Irina Mihaela Ciomaga ${ }^{1,2}$, \\ Nicolai Nistor ${ }^{1,2}$ \\ 1"Grigore T. Popa" University of Medicine and Pharmacy, Iasi, Romania \\ 2"Sf. Maria" Emergency Hospital for Children, lasi, Romania \\ ${ }^{3}$ Pneumology Clinical Hospital, Iasi, Romania
}

\begin{abstract}
Communication is a vital skill in the medical world and it differs from the communication in any other areas due to the particular problems that are exposed and their intimate nature. The talent to speak effectively with the patient constitutes a basic element in achieving a safe and successful medical act. The art of conversation in the relationship between the doctor and his patient must be learned and mastered with craftsmanship especially when the patients are children. Because communication is the most common "medical procedure", it is important for the physician to have the ability to communicate openly, to show tolerance and compassion for the patient, in order to carry out an effective daily medical activity.

Diagnostic errors in pediatrics represent a branch which is less explored and accepted. Mistakes are not easy to accept by anyone, and doctors make no exception. In order to carry out his activity in optimum conditions, a doctor must be versed not only in pediatrics pathology, but also in child psychology.
\end{abstract}

Keywords: child, conversation, errors

\section{GENERAL REVIEWS}

How the doctor approaches the patient is not only a therapeutic act or only about moral, but both of them at the same time. Communication is something that can be learned and can play an important role in understanding the suffering of the patient. We can say that it is a simple thing that comes naturally, but most often it requires tact and patience to get the correct information, especially with the pediatric patient. The first rule for a correct communication is listening very carefully. Another important element is the quality of the conversation. For instance it is not enough to just talk to a child if you do not give him enough credit or you do not listen to him. Providing information is also often a defining aspect for an effective doctor - patient conversation. Regardless of their age, patients expect the doctor to provide information that satisfy two types of needs: cognitive and affective. Cognitive needs are defined by information that the patient wants to know about his illness, in children`s case they want to know what made them sick, how many days they have to spend in the hospital, what will they be allowed to eat when they get home, etc.

Affective needs - that are meant to bring the patient wellbeing and to make him feel that he is understood, supported and helped by his doctor (1).

For the pediatric patient who is suffering, the doctor can seem as a powerful being, full of energy, sometimes even magical. The doctor's work is often a succession of emotions.

The quality of medical information obtained during consultations is closely linked to the doctor's ability to ask questions and to create a relationship with the patient. Every physician creates a unique atmosphere through its individual ways of practicing medicine, and in the relationship with his patient, the doctor seeks to convert him to adopt his style $(1,5)$.

In the communication with the patient of pediatric age, the doctor must ensure that the message sent was properly understood by the child, correct- 
ly received, what is the feedback, so the next step to trigger an active listening. Active listening refers to understanding and receiving the message, and includes encouraging the discussion partner through a series of gestures and behaviours aimed at capturing attention, developing interest in discussion and gaining confidence. Another defining aspect in the doctor-patient relation is the ability of the former to approximate the child, giving the necessary psychological comfort, thus avoiding the lies told often out of fear.

Children go through progressive stages of moral development. After watching his two and a half year old son, Darwin suggested that even children of this age are able to tell lies, but a two year old may not understand the concept of truth versus falsehood. This phenomenon occurs when the child acquires the mind theory and learns that adults can not read other people's thoughts and providing false information that can help them to overcome a difficult situation. Preschool children, older than 4-6 years refine their manner of lying.

Learning to deceive and to tell the truth is a natural part in the development process of any child. Depending on the situation and their motivation, kids can lie:

- to avoid negative consequences or punishment;

- to test adults responses and reactions;

- to manipulate adults in the sense of getting what they want;

- to attract attention even when they know that adults know the truth.

To identify a lie it must be considered why a person would hide the truth. The best example is the child who does not want to be punished. Sometimes lying can continue to cover other lies of the past (2).

Anyone would like to know when he is lied to, but sometimes we find ourselves in a situation where we accept a lie just because the truth can not be proven. If a patient is fantasizing right from the first meeting, he will be the first victim of his lies. Many pediatric patients are not fully aware of the seriousness of a lie or of a hidden element.

It is essential to recognize that lying may be an early indicator of more severe problems. Compulsive Lying was often shown in the early stages of children suffering from social behaviour disorders, especially ADHD and conduct disorders.

Diagnostic errors in pediatrics represent a branch that has so far been little studied, developed and supported. The information that we have is extremely limited and occur most often out of known malpractice cases. These cases are unrepresentative because they cover a low spectrum of diagnostic errors, errors that have a low frequency and high severity (2).

The medical necessity of a new branch that deals strictly with the detection and quantification of diagnostic error is a controversial topic today. Mark Graber, the founder and president of the "Society of Improving Diagnosis" in US said that he does not know somewhere in the world to exist an organization that deals with the monitorisation of diagnostic errors. Also, no hospital in the world has implemented a program to detect errors that are made within the medical institution (1).

This necessity stems out of the statistical results obtained in the few studies conducted so far. A study from 2014 made in the United States of America stated that almost every person will receive at least one misdiagnosis in their lifetime, sometimes with devastating consequences (1). In the United States of America almost 12 million children receive a wrong diagnosis each year and $32 \%$ of malpractice cases occur due to diagnostic errors (2).

We are faced most frequently with a diagnostic error when the:

- Diagnosis is late;

- Diagnosis is initially wrong;

- Diagnosis is never made (2).

The main factors influencing the diagnostic decision are:

1. The health system;

2. Workflow;

3. Medical knowledge and clinical judgment;

4. Input from carers and from the child himself.

1. The health system is defined by limited resources and limited access or delayed medication and/or informatical procedures that raises more problems especially since the introduction of the health card.

2. Flooded workload is due to staff shortages associated with the large number of patients assigned to each doctor. Another aspect is given by the number of hours spent daily in the hospital and the large number of shifts in a month.

If the health system and the large workflow are common factors for all the specialties, the last two factors (medical knowledge and clinical judgment and also the input from carers and the child) are more specific for the pediatric branch.

3. Information received from caregivers and pediatric patients 
A study published in the Pediatric Journal, in 2010, stated that the main cause of diagnostic errors in pediatrics is given by erroneous information received from the caregivers and the pediatric patients.

The main causes that led to diagnostic errors were:

- Erroneous information received from the patient or their caregivers and incomplete clinical examination;

- System Factors: lack of communication and coordination in the medical team (2).

4. Medical knowledge and clinical judgment

David Meyers, the head of the Emergency Unit of the US, stated that: "Medicine is too complicated for a simple man. There are many information that must be processed and the work environment is full of troublemakers. We can never be sure how much credit or how much importance to give each incoming information" (1).

For a pediatrician to be able to practice to an optimum level, he should posses a rich baggage of knowledge. Apart from the necessary knowledge for diagnosing the patient and for establishing the right treatment, the pediatrician must have sound knowledge of the child's psychological development at every stage of its development.

Helene Epstein, author of the article "Why It's So Easy for Doctors to misdiagnose Kids", published in The Atlantic Journal stated that: "Doing everything right is infinitely more difficult when patients do not know the right words to describe what they feel" (3).

This statement fits very well for small children (2-4 year olds). If adults know their body well enough and can realize easily when they are ill and what is bothering them, for children, unless we are talking about an acute pain, high fever or trauma, do not realize always that they have a problem. For example, they may not realize that they feel more fatigued than normal or should not have daily headaches. In other cases, even if they realize that something is wrong, they don't poses the right words in order to express themselves.

Older children and adolescents raises other problems that could put a pediatrician in difficulty. They tend to hide some details about their lives that might seriously impair their health like trauma during sports, drugs, pill taking or sexual activity. (4)

\section{CONCLUSIONS}

Any pediatrician should have extensive knowledge in the field of child psychology. Love and devotion to the sick child must be filled with a sharp spirit of observation, the ability to communicate with children and readiness for therapeutic intervention.

The quality of medical information obtained during consultations is closely linked to the patient's ability to ask questions and to create a relationship with him. Every physician creates a unique atmosphere through its individual ways of practicing medicine.

The emergence of a new branch that deals with the detection and quantification of diagnostic errors is vital, both for the protection of the patient and of the doctor and for a better development of the medical system.

Conflict of interest: none declared Financial support: none declared

\section{REFERENCES}

1. Croskerry P. Diagnostic failure: A cognitive and affective approach. In Advances in Patien Safety: From research to implementation. Volume 2: Concepts and methodology. Agency for Healthcare Research and Quality. 2005

2. Singh H., Thomas E.J., Wilson L. et al. Errors of Diagnosis in Pediatric Practice: A Multi-Site Survey. Pediatrics. 2010

3. Epstein H. Why It's so Easy for Doctors to Misdiagnose Kids. The Atlantic. 2015

4. Kuhn G.J. Diagnostic errors. Acad Emerg Med. 2002

5. Schiff G.D., Hasan O., Kim S., et al. Diagnostic Error in Medicine: Analysis of 583 Physician-Reported Errors. Arch Intern Med. 2009

6. Singh H., Weingart S. Diagnostic Errors in Ambulatory Care: Dimensions and Preventive Strategies. Adv Health Sci Educ Theory Pract. 2009 